\title{
SUSTAINABILITY THOUGHTS 102: HOW THE SHIFT FROM TRADITIONAL MARKETS TO SUSTAINABILITY MARKETS WOULD HAVE LOOKED LIKE HAD THE 1987 BRUNDTLAND COMMISSION RECOMMENDED THEN A SUSTAINABILITY FIX?
}

\author{
Lucio Muñoz* \\ Independent qualitative comparative researcher/consultant, Vancouver, BC, Canada \\ http://doi.org/10.35409/IJBMER.2020.3171
}

\begin{abstract}
It can be said that the traditional market is a free market that brings together traditional producers $(\mathrm{K})$ and traditional consumers $(\mathrm{L})$ under the assumption of full social and environmental externality neutrality. And this create a circular traditional economy illusion, the idea that production activity can take without generating production and consumption externalities. The fact that the social and environmental externalities associated with the traditional market are real leads to a disconnect between social and environmental externalities and traditional market pricing. In order to correct this disconnect, the 1987 Brundtland Commission recommended the use of sustainable development thinking, which was the wrong recommendation since the externality problem affecting the traditional market was and is a sustainability issue, not a sustainable development issue. There were 3 possible corrections to this sustainability problem: i) a full social and environmental externality correction or sustainability fix; ii) a partial correction through green markets or an environmental sustainability fix; and iii) a partial correction through red markets or a social sustainability fix. The discussion above raises some interesting questions depending of the type of fix that is recommended. With respect to the first possibility, the question is how the shift from the traditional market model of Adam Smith towards sustainability markets would have looked like had the 1987 Brundtland Commission recommended then a sustainability fix? The main goal of this paper is to provide an answer to this question.
\end{abstract}

Keyword: Environmental externality, social externality, Traditional market, sustainability, sustainability market, cost internalization, cost externalization, externality neutrality assumption, circular traditional market illusion, circular sustainability market, the traditional market price, the sustainability market price.

\section{INTRODUCTION}

\section{a) The structure of the traditional market of Adam Smith}

It can be said that the traditional market(TM) is a free market that brings together traditional producers $(\mathrm{K})$ and traditional consumers $(\mathrm{L})$ under the assumption of full social and environmental externality neutrality, a situation that has been recently summarized(Muñoz 2020) 
International Journal of Business Management and Economic Review

Vol. 3, No. 02; 2020

ISSN: 2581-4664

as follows:

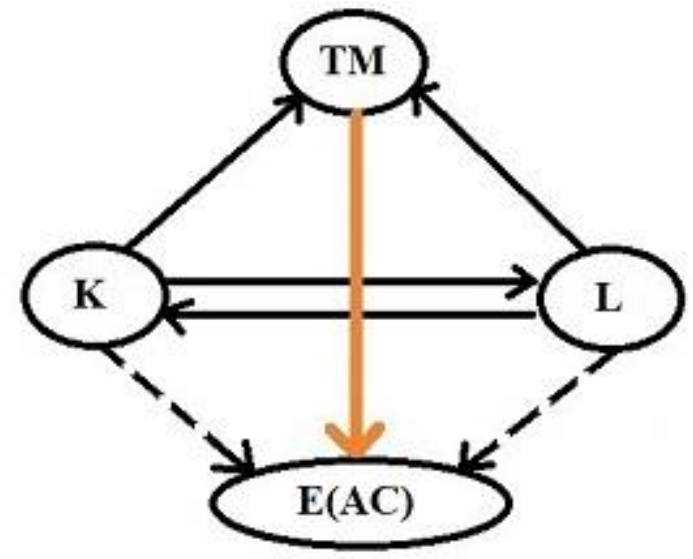

Figure 1 The structure of the traditional market

Figure 1 above tells us the following about the traditional market(TM): i) social and environmental externalities[E(AC)] are exogenous issues to the model so they are externalized as indicated by the continuous orange arrow from $\mathrm{TM}$ to $\mathrm{E}(\mathrm{AC})$; ii) traditional production(K) and traditional consumption(L) externalities are irrelevant as indicated by the broken black arrows from $\mathrm{K}$ and $\mathrm{L}$ to $\mathrm{E}(\mathrm{AC})$; iii) traditional producers $(\mathrm{K})$ and traditional consumers $(\mathrm{L})$ interact freely in the traditional market(TM) as indicated by the continuous and opposing black arrows between $\mathrm{K}$ and $\mathrm{L}$; iv) the traditional market price $(\mathrm{TMP}=\mathrm{P})$ is determined then by the free interaction of traditional supply $(\mathrm{K})$ and traditional demand(L) as indicated by the continuous black arrows from $\mathrm{K}$ and $\mathrm{L}$ to $\mathrm{TM}$; and v) the model operates under rationality and fully independent choices.

\section{b) The circular traditional market illusion}

Since according to Figure 1 above social and environmental externalities[E(AC)] are assumed irrelevant in the traditional market model(TM), then they can be left out of the model, which leads to the circular traditional market illusion depicted in Figure 2 below:

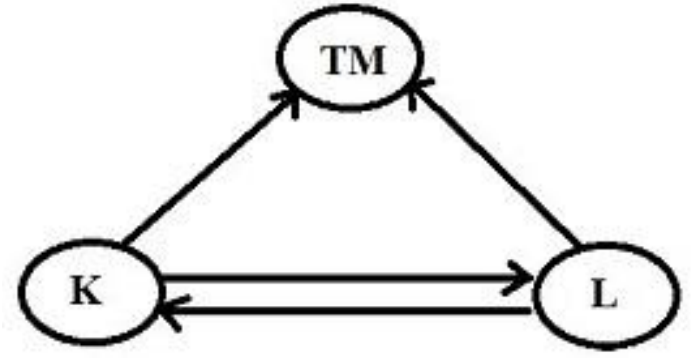

Figure 2 The circular traditional economy illusion

Figure 2 above simply says economic activity and economic growth take place in the traditional market(TM) without producing social and environmental effects[E(AC) $=0]$, which is the thought behind the circular traditional market illusion. In other words, we produce and 


\section{International Journal of Business Management and Economic Review}

Vol. 3, No. 02; 2020

ISSN: 2581-4664

consume under zero social and environmental externality impact when operating under the full externality neutrality assumption. This assumption makes the traditional market(TM) a distorted market in social and environmental terms(Muñoz 2010).

\section{c) The externality problem affecting the sustainability of the traditional market model}

As it is a fact that production and consumption externalities associated with economic activity[E(AC)] are real, then there is a disconnect between the pricing mechanism of the traditional market(TMP $=\mathrm{P})$ and social and environmental externalities[E(AC)] that need to be accounted for, which leads to the externality problem affecting the sustainability of the traditional market model(TM) as indicated in Figure 3 below:

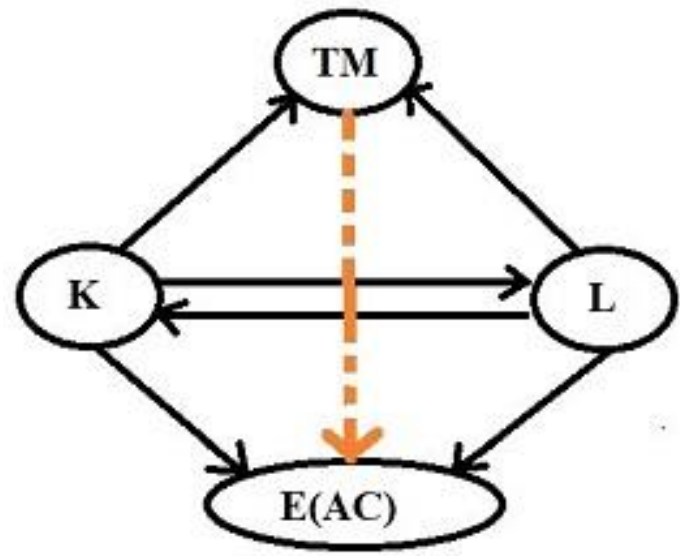

Figure 3 The externality problem affecting the traditional market model(TM)

The broken orange arrow between $\mathrm{TM}$ and $\mathrm{E}(\mathrm{AC})$ in Figure 2 above represents the externality problem affecting the sustainability of the traditional market(TM) as the relevant externalities indicated by the continuous black arrows from $\mathrm{K}$ and $\mathrm{L}$ to $\mathrm{E}(\mathrm{AC})$ are not accounted for in the traditional market price(TMP $=\mathrm{P}$ ) of the traditional market(TM). As indicated recently, correcting now the externality problems in Adam Smith's traditional market model has led us to approaching sustainability backwards in terms of economic ideas(Muñoz 2012)

\section{d) The 1987 Brundtland commission's sustainable development solution to a sustainability problem}

The Brundtland commission in 1987(WCED 1987) saw the social and environmental disconnect indicated in Figure 3 above under which business as usual had been operating; and it called for solutions to this social and environmental disconnect through sustainable development means. The Brundtland commission in 1987 apparently failed to see that the externality problem affecting the traditional market model of Adam Smith detailed in Figure 3 above was and is a sustainability problem, not a sustainable development problem; and therefore, the Brundtland Commission recommended the wrong approach to deal with the sustainability problem. There were 3 possible corrections to this sustainability problem depicted in Figure 3 above: i) a full social and environmental externality correction or sustainability fix; ii) a partial correction through green markets or an environmental sustainability fix; and iii) a partial correction through 


\section{International Journal of Business Management and Economic Review}

Vol. 3, No. 02; 2020

ISSN: 2581-4664

red markets or a social sustainability fix. It has been pointed out that using sustainable development tools to address a sustainability problem is a direct violation of the theory-practice consistency principle(Muñoz 2009), and if we do so we are using tools that are inconsistent with the nature of the problem we are trying to solve.

\section{e) The need to understand the nature of a full fix through sustainability markets to the externality problem affecting Adam Smith's model}

The discussion above raises some interesting questions depending of the type of fix that is recommended. With respect to the first possibility, the question is how the shift from the traditional market model of Adam Smith towards sustainability markets would have looked like had the 1987 Brundtland Commission recommended then a sustainability fix? The main goal of this paper is to provide an answer to this question.

\section{GOALS OF THIS PAPER}

i) To highlight the structure the sustainability fix to the externality problem affecting Adam Smith's traditional market model; ii) To stress the structure of the circular sustainability based economy associated with the sustainability fix; and iii) To point out the socioenvironmental externality gap or socio-environmental sustainability gap embedded in the circular traditional market illusion.

\section{METHODOLOGY}

First, the terminology used in this paper is shared. Second, the operational concepts and externalization and internalization rules supporting this paper are discussed. Third, the structure the sustainability fix to the externality problem affecting Adam Smith's traditional market model and its implications are shared. Fourth, the structure of the circular sustainability based economy associated with the sustainability fix; and its implications are highlighted. Fifth, the structure of the circular traditional market illusion in the face of real externality costs is shared to highlight the social and environmental sustainability gap or social and environmental externality gap embedded in the traditional market. Finally, some food for thoughts and relevant conclusions are provided.

\section{Terminology}

$\mathrm{A}=$ active social system

$\mathrm{B}=$ active economic system

$\mathrm{C}=$ active environmental system

$\mathrm{TM}=$ traditional market

$\mathrm{K}=$ traditional producers/supply

SK = sustainability producers/supply $\mathrm{a}=$ passive social system

$\mathrm{b}=$ passive economic system

$\mathrm{c}=$ passive environmental system

$\mathrm{SM}=$ sustainability market

$\mathrm{L}=$ traditional consumers/demand

$\mathrm{SL}=$ sustainability consumers/demand

SEEM = socio-environmental externality management $\quad M_{i}=$ market type $i$

$\mathrm{E}(\mathrm{T})=$ externalization of $\mathrm{T}$

$\mathrm{I}(\mathrm{t})=$ internalization of $\mathrm{t}$

$\mathrm{E}(\mathrm{AC})=$ externalization of $\mathrm{A}$ and $\mathrm{C}$

$\mathrm{I}(\mathrm{ac})=$ internalization of $\mathrm{a}$ and $\mathrm{c}$

TMP $=$ traditional market price

$\mathrm{SMP}=$ sustainability market price

SESG $=$ socio-environmental sustainability gap $\mathrm{E}(\mathrm{T})=$ externalization of $\mathrm{T}$ 
International Journal of Business Management and Economic Review

Vol. 3, No. 02; 2020

ISSN: 2581-4664

SEEG $=$ socio-environmental externality gap $\quad I(t)=$ internalization of $t$

\section{Operational concepts and externalization and internalization rules} i) Operational concepts

1) Traditional market, the economy only market

2) Sustainability market, the socially and environmentally friendly market.

3)Traditional market price, the general market economic only price or the price that covers the cost of production at profit $(T M P=E C M+i=P)$ or zero profit $(T M P=E C M=P)$.

4) Sustainability market price, the price that reflects the economic, social, and the environmental cost of production or the price that covers the cost of socially and environmentally friendly production.

5) Cost externalization, the leaving out of the pricing mechanism of the market relevant costs associated with production.

6) Social cost externalization, the leaving out of the pricing mechanism of the market the social costs associated with production.

7) Environmental cost externalization, the leaving out of the pricing mechanism of the market the environmental costs associated with production.

8) Economic cost externalization, the leaving out of the pricing mechanism of the market the economic costs associated with production.

9) Cost externalization assumption neutrality, the assumption that production has minimal or no cost impact on external factors to a market model.

10) Full costing, the reflecting in the pricing mechanism of the market all cost associated with production; there are no market distortions.

11) Partial costing, not reflecting in the pricing mechanism of the market all cost associated with production; there are partial market distortions.

12) No costing, not reflecting in the pricing mechanism of the market any costs associated with production; there is full market distortion.

13) Full inclusion, all factors are endogenous to the model, there are no exclusions.

14) Partial inclusion, some factors are exogenous to the model, there are some exclusions.

15) Fully independent development choices, when we have individual development choices unrelated to each other or pure choices such as society only $(A)$, economy only $(B)$, and environment only $(C)$. In this world only fully independent development choices exist so the set = $\{A, B, C\}$. This is the world of the Arrow Impossibility theory and theorem.

16) Partially codependent development choices, when we have mixed/paired development choices such as socio-economy $(A B)$, socio-environment $(A C)$, and eco-economy $(B C)$. In this universe only codependent development choices exist so the set $=\{A B, A C, B C\}$. This is outside the normal world of the Arrow Impossibility theory and theorem.

17) Fully codependent development choices, when all development choices are mixed together such as the socio-economy-environment $(A B C)$ model. In this paradigm only fully codependent development choices exist so the set $=\{A B C\}$. This is outside the world of the Arrow Impossibility theory and theorem. 
Vol. 3, No. 02; 2020

ISSN: 2581-4664

18) Full cost externalization, all costs associated with production are not reflected in the pricing mechanism of the market.

19) Partial cost externalization, some costs associated with production are not reflected in the pricing mechanism of the market.

20) No cost externalization, all costs associated with production are reflected in the pricing mechanism of the market.

21) Full cost internalization, all costs associated with production are reflected in the pricing mechanism of the market.

22) Partial cost internalization, some costs associated with production are reflected in the pricing mechanism of the market.

23) No cost internalization, all costs associated with production are not reflected in the pricing mechanism of the market.

24) Externalities, factors assumed exogenous to a model

25) Full externality assumption, only one component is the endogenous factor in the model; the others are exogenous factors.

26) Partial externality assumption, not all factors are endogenous factors at the same time in the model.

27) No externality assumption, all factors are endogenous factors at the same time in the model.

28) Economic externality, the economic costs associated with production not reflected in the pricing mechanism of the market.

29) Social externality, the social cost associated with production not reflected in the pricing mechanism of the market.

30) Environmental externality, the environmental cost associated with production not reflected in the pricing mechanism of the market.

31) Green or environmental margin, to cover the extra cost of making the business environmentally friendly.

32) Social margin, to cover the extra cost of making the business socially friendly.

33) Economic margin, to cover only the economic cost of production

34) Profit, the incentive to encourage economic activity

35) Full cost price, a price that reflects all costs associated with production.

36) Some cost price, a price that reflects only some costs associated with production.

37) No cost price, a price that does not reflect any cost associated with production.

38) Circular market illusion, the idea that production activity can take place without producing relevant externalities.

39) Circular traditional economy illusion, the idea that production activity can take place without producing relevant social and/or environmental externalities.

40) Circular sustainability based economy, the idea that market prices reflect the cost of making business social and environmentally friendly in order to cover the cost of dealing with the social and environmental externalities they create to close the free market cycle productionconsumption-socioenvironmental externality.

\section{ii) Externalization rules}

Let's assume we have a market with two relevant components, society(A) and 


\section{International Journal of Business Management and Economic Review}

Vol. 3, No. 02; 2020

ISSN: 2581-4664

environment $(\mathrm{C})$, where $\mathrm{A}=$ active component, $\mathrm{a}=$ passive component, $\mathrm{C}=$ active component, and $\mathrm{c}=$ passive component, then the externalization rules(E) work as follows:

1) $\mathbf{E}(\mathbf{A})=\mathbf{a} \quad \rightarrow-\rightarrow$ relevant social costs $(A)$ are assumed irrelevant

2) $\mathbf{E}(\mathbf{C})=\mathbf{c} \quad-\rightarrow-\rightarrow$ relevant environmental cost $(C)$ are assumed irrelevant

3) $\mathbf{E}(\mathbf{A C})=\mathbf{a c} \quad \rightarrow-\rightarrow$ relevant social costs and economic costs $(A C)$ are assumed irrelevant

\section{iii) Internalization rules}

Let's assume we have a market with two relevant components, society(A) and environment $(\mathrm{C})$, where $\mathrm{A}=$ active component, $\mathrm{a}=$ passive component, $\mathrm{C}=$ active component, and $\mathrm{c}=$ passive component, then the internalization rules(I) work as follows:

4) $\mathbf{I}(\mathbf{a})=\mathbf{A} \quad \rightarrow--\rightarrow$ irrelevant social costs $(a)$ are now relevant

5) $\mathbf{I}(\mathbf{c})=\mathbf{C} \quad----\rightarrow$ irrelevant environmental costs $(c)$ are now relevant

6) $\mathbf{I}(\mathbf{a c})=\mathbf{A C} \quad----\rightarrow$ irrelevant social costs and economic costs (ac) are now relevant

iv) Model structure and externalization rules

Let's assume we have the following three market structures $\mathrm{M} 1=\mathrm{ac}, \mathrm{M} 2=\mathrm{Ac}$ and M3 = $\mathrm{AC}$, then the following holds true:

7) $\mathbf{M 1}=\mathbf{a c}=\mathbf{E}(\mathbf{A C})=$ a fully irresponsible market as all costs are externalized

8) $\mathbf{M} 2=\mathbf{A c}=[\mathbf{I}(\mathbf{a})][\mathbf{E}(\mathbf{C})]=$ a partially responsible market as social cost is internalized

9) $\mathbf{M 3}=\mathbf{A C}=[\mathbf{I}(\mathbf{a})][\mathbf{I}(\mathbf{c})]=$ a fully responsible market as all costs are internalized.

\section{v) Reversing externalization rules}

Let's assume we have a market with two relevant components, society(A) and environment $(\mathrm{C})$, where $\mathrm{A}=$ active component, $\mathrm{a}=$ passive component, $\mathrm{C}=$ active component, and $\mathrm{c}=$ passive component, then the process of reversing externalization-internalization rules works as follows:

The case of internalizing the externality: if $\mathrm{E}(\mathrm{AC})=\mathrm{ac}$, the following holds true:

10) $\mathbf{I}[\mathbf{E}(\mathbf{A C})]=\mathbf{I}(\mathbf{a c})=\mathbf{A C}$, internalization-externalization forces cancel each other out

The case of externalizing the internality: if $\mathrm{I}(\mathrm{ac})=\mathrm{AC}$, the following holds true:

11) $\mathbf{E}[\mathbf{I}(\mathbf{a c})]=\mathbf{E}(\mathbf{A C})=\mathbf{a c}$, externalization-internalization forces cancel each other out

\section{The structure of the sustainability market(SM) fix}

To fully fix the externality problem affecting the sustainability of the traditional market model(TM) summarized in Figure 3 above and to be able to fulfill the Brundtland Commission's wish of making business as usual model a fully social and environmental externality friendly model we have to recognize two things: i) Social and environmental externalities[E(AC)] are real; and ii) hence they must be internalized in the pricing mechanism of the traditional market $(\mathrm{TMP}=\mathrm{P})$. The internalization of social and environmental costs $\{\mathrm{I}[\mathrm{E}(\mathrm{AC})]\}$ in the pricing mechanism of the traditional market(TM) leads to a shift to sustainability markets(SM) or socially and environmentally friendly markets, a situation summarized in Figure 4 below: 
Vol. 3, No. 02; 2020

ISSN: 2581-4664

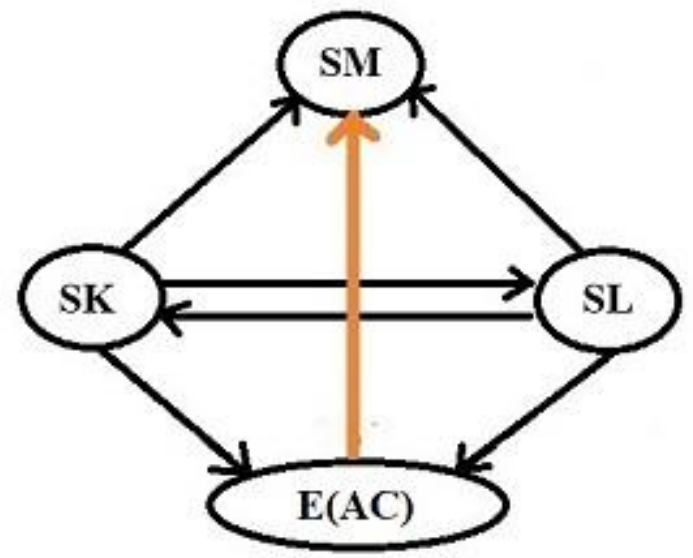

Figure 4 The way the sustainability solution to the exteruality problem affecting Adam Smith's model would have looked like if 1987 Brundtland Commission would have reccomended to do so.

Figure 4 above tells us the following about the sustainability market(SM) or socially and environmentally friendly markets: i) if you internalize the social and environmental externalities(E[AC]) in the pricing mechanism of the traditional market(TMP $=\mathrm{P}$ ) you shift the traditional market model(TM) towards sustainability markets(SM) as indicated by the continuous orange arrow from $\mathrm{E}[\mathrm{AC}]$ to $\mathrm{SM}$; ii) the sustainability market(SM) is driven by sustainability supply/producers(SK) and sustainability demand/consumers(SL) as indicated by the opposing continuous black arrows between SK and SL; iii) in the sustainability market(SM) the free interaction of sustainability or socially and environmentally friendly producers(SK) and sustainability or social and environmentally friendly consumers(SL) determines a full cost price or sustainability market price(SMP) as indicated by the continuous arrows from SK and SL to $\mathrm{SM}$; iv) this is a market where social and environmental externalities are relevant as indicated by the continuous black arrows from SK and SL to E(AC); and v) the sustainability market(SM) operates under rationality and fully codependent choices or socio-eco-economic choices.

In other words, based on Figure 4 above it can be said that the sustainability market(SM) is a free market that brings together sustainability producers $(\mathrm{K})$ and sustainability consumers(L) under conditions of no social and environmental externality neutrality or under full costing.

\section{The structure of the circular sustainability based economy}

Since under the sustainability markets(SM) the sustainability market price(SMP) reflects the social and environmental costs of production[I(ac)], then the sustainability market generates the resources needed to deal with the social and environmental cost associated with economic activity, closing the cycle sustainability production-sustainability consumption-socioenvironmental externalities as indicated by the connecting yellow arrows in Figure 5 below: 


\section{International Journal of Business Management and Economic Review}

Vol. 3, No. 02; 2020

ISSN: 2581-4664

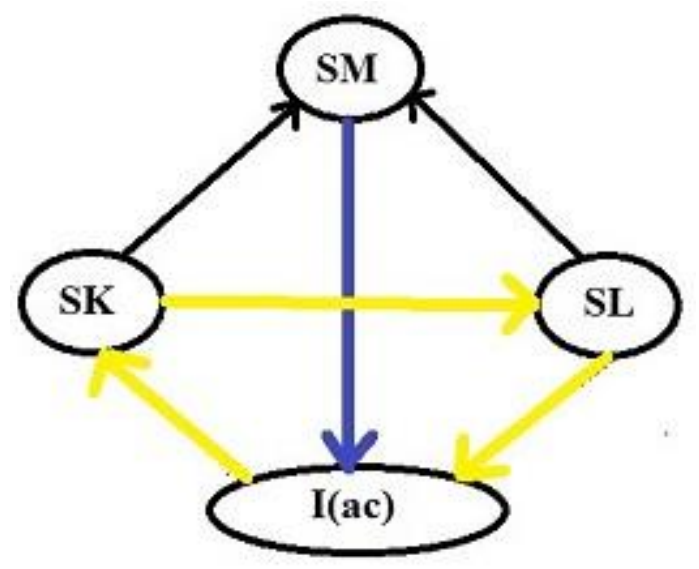

Figure 5 The structure of the circular sustainability based economy

We can see in figure 5 above that social and environmental costs[E(AC)] in the sustainability market(SM) are now endogenous issues[I(ac)] to the model as indicated by the blue line. Hence, sustainability markets(SM) take responsibility for the externalities they produce so they generate the resources needed to create and support the programs and/ businesses necessary to close or deal with the externality gap. The circular sustainability market structure in Figure 5 above indicated by the continuous yellow arrows KS, SL, I(ac) represents an end to the circular traditional market's social and environmental externality neutrality illusion that social and environmental costs do not matter as here all costs related to economic activity are accounting for.

In other words, full costing transforms the sustainability market(SM) and its circular structure production(SK), consumption(SL), and social and environmental externalities internalization $[(\mathrm{I}(\mathrm{ac})]$ into fully responsible structures in social and environmental terms as indicated by the continuous yellow arrow circling SK-SL-I(ac) in Figure 5 above. Hence, there are no socio-environmental externality gaps(SEEG) or socio-environmental sustainability gaps(SESG) in sustainability markets(SM) as they are socially and environmentally friendly markets.

\section{The externality gap affecting the circular traditional market illusion}

Since under the traditional markets(TM) the traditional market price $(\mathrm{TMP}=\mathrm{P})$ does not reflect the social and environmental costs of production[E(AC)], then the traditional market does not generate the resources needed to deal with the social and environmental cost associated with economic activity, passing them to society as a whole, leaving open the cycle traditional production-traditional consumption-externalities as indicated in Figure 6 below: 


\section{International Journal of Business Management and Economic Review}

Vol. 3, No. 02; 2020

ISSN: 2581-4664

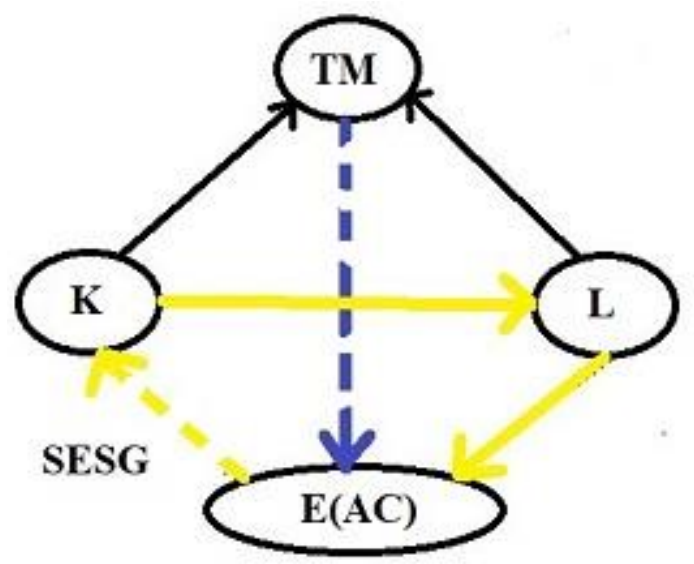

Figure 6 The externality gap embedded in the circular traditional market(TM) illusion

We can appreciate in figure 6 above that in the traditional market(TM) social and environmental costs[E(AC)] are exogenous issues to the model so they are externalized as indicated by the broken blue line. Therefore, traditional markets do not take responsibility for the social and environmental externalities they produce and therefore, they do not generate the resources needed to create and support the programs and/ businesses needed to close the socioenvironmental externality gap(SEEG) or socio-environmental sustainability gap(SESG) they create, leaving it open as indicated by the broken yellow arrow from $\mathrm{E}(\mathrm{AC})$ to $\mathrm{K}$; and hence passing this way the responsibility to deal with those externalities to society as a whole.

In other words, there is a social and environmental externality gap(SEEG) or socioenvironmental sustainability gap(SESG) embedded in the circular traditional market illusion as in this market relevant social and environmental costs related to economic activity are not accounting for. Partial costing(economic costing only) transforms the traditional market(TM) and its circular structure production $(\mathrm{K})$, consumption(L), and social and environmental externality externalization $[(\mathrm{E}(\mathrm{AC})]$ into distorted or irresponsible structures in social and environmental terms as indicated by the broken yellow arrow in the circle K-L-E(AC) in Figure 6 above.

Notice that the existence of this embedded social and environmental sustainability gap(SESG) or social and environmental externality gap(SEEG) indicated in Figure 6 above provides rational for the existence of socio-environmental externality management markets or programs(SEEM) designed to produce the funds needed to manage social and environmental externalities without attempting to correct the root cause of the externality generation and accumulation problem associated with the traditional market, a distorted traditional market price. Finally, when comparing Figures, we can see that the closing of the socio-environmental sustainability gap(SESG) represented by the broken yellow arrow in Figure 6 leads to the structure of the circular sustainability based economy presented in Figure 5 above, where there are no socio-environmental sustainability gaps as indicated by the continuous yellow arrow going from $\mathrm{I}(\mathrm{ac})$ to $\mathrm{SK}$. 


\section{International Journal of Business Management and Economic Review}

Vol. 3, No. 02; 2020

ISSN: 2581-4664

\section{Food for thoughts}

Is there a sustainable development solution to a sustainability problem? I think no, what do you think?; Can we solve a sustainability problem by attacking the consequences? I think no, what do you think?; and Are externality management markets free markets? I think no, what do you think?

\section{CONCLUSIONS}

First, it was highlighted that the shift from traditional market to sustainability markets requires the internalization of the social and environmental cost associated with economic activity. Second, it was indicated that when social and environmental cost internalization takes place the circular traditional economy illusion ends as now all costs are reflected in the pricing mechanism of the sustainability market. Third, it was pointed out that as the sustainability market takes responsibility for the externalities it produces it generates the resources needed to close the sustainability cycle sustainability production-sustainability consumption-externalities. Fourth, it was stressed that as the traditional market does not take responsibilities for the externalities it produces, there is a social and environmental externality gap or socio and environmental sustainability gap preventing the closing of the traditional production-traditional consumption-socio-environmental externality cycle when full externality accounting becomes binding. Finally, it was indicated that the existence of this embedded social and environmental externality or sustainability gap in the traditional market and its circular market illusion provides the opportunity to deploy externality management approaches to keep social and environmental externalities within a bearable level.

\section{REFERENCES}

Muñoz, Lucio, 2009. Beyond Traditional Sustainable Development: Sustainability Theory and Sustainability Indices Under Ideal Present-Absent Qualitative Comparative Conditions, In: Mineria Sustentable, REDESMA, Vol.3(1), March, La Paz, Bolivia.

Muñoz, Lucio, 2010. What If Markets Have Always Been Distorted? Would It Then Be a Good Fix to Add Fair Trade Margins to Correct Distorted Agricultural Market Prices?, Journal of Sustainability, Issue 2, Number 4(Spring), Rio Rancho, New Mexico USA.

Muñoz, Lucio, 2012. Complex and Man-Made Markets: Are We Currently Approaching Sustainability in a Backward and More Chaotic Way in Terms of Economic Thinking?, In: The Mother Pelican Journal, Vol. 8, No. 8, August, Ed. Luis Gutierrez, PhD, USA.

Muñoz, Lucio, 2020. Sustainability thoughts 101: What was wrong with the structure of Adam Smith's traditional market model? What are the main implications of this?. Boletin CEBEM-REDESMA, Año 14, No.2, February, La Paz, Bolivia.

World Commission on Environment and Development(WCED), 1987. Our Common Future, Oxford University Press, London, UK. 